\title{
Influence of an acetate- and a lactate-based balanced infusion solution on acid base physiology and hemodynamics: an observational pilot study
}

Klaus F Hofmann-Kiefer ${ }^{*}$, Daniel Chappell ${ }^{\dagger}$, Tobias Kammerer, Matthias Jacob, Michaela Paptistella, Peter Conzen and Markus Rehm

\begin{abstract}
Background: The current pilot study compares the impact of an intravenous infusion of Ringer's lactate to an acetate-based solution with regard to acid-base balance. The study design included the variables of the Stewart approach and focused on the effective strong ion difference. Because adverse hemodynamic effects have been reported when using acetate buffered solutions in hemodialysis, hemodynamics were also evaluated.
\end{abstract}

Methods: Twenty-four women who had undergone abdominal gynecologic surgery and who had received either Ringer's lactate (Strong lon Difference $28 \mathrm{mmol} / \mathrm{L} ; \mathrm{n}=12$ ) or an acetate-based solution (Strong lon Difference 36.8 $\mathrm{mmol} / \mathrm{L} ; \mathrm{n}=12$ ) according to an established clinical protocol and its precursor were included in the investigation. After induction of general anesthesia, a set of acid-base variables, hemodynamic values and serum electrolytes was measured three times during the next 120 minutes.

Results: Patients received a mean dose of $4,054 \pm 450 \mathrm{ml}$ of either one or the other of the solutions. In terms of mean arterial blood pressure and norepinephrine requirements there were no differences to observe between the study groups. pH and serum $\mathrm{HCO}_{3}^{-}$concentration decreased slightly but significantly only with Ringer's lactate. In addition, the acetate-based solution kept the plasma effective strong ion difference more stable than Ringer's lactate.

Conclusions: Both of the solutions provided hemodynamic stability. Concerning consistency of acid base parameters none of the solutions seemed to be inferior, either. Whether the slight advantages observed for the acetate-buffered solution in terms of stability of $\mathrm{pH}$ and plasma $\mathrm{HCO}_{3}^{-}$are clinically relevant, needs to be investigated in a larger randomized controlled trial.

Keywords: Acetate, Lactate, Balanced infusion solution, Acid-base balance, Hemodynamic stability

\section{Background}

In the fields of surgery and intensive care, hyperchloremic acidosis is a well-known problem in patients receiving large amounts of standard crystalloids, especially $0.9 \%$ sodium chloride solutions. A series of investigations has emphasized the disadvantageous effects of hyperchloremic acidosis on various organ systems, for

\footnotetext{
* Correspondence: Klaus.Hofmann-Kiefer@med.uni-muenchen.de

${ }^{\dagger}$ Equal contributors

Clinic of Anesthesiology, Ludwig-Maximilians University, City of Munich, Germany
}

example, hemodynamics, NO-production, renal blood circulation, urinary output or hemostasis [1-4]. Balanced crystalloids, whose composition prevents hyperchloremia, are increasingly accepted and likely to be 'state of the art' in the near future [3,5-7]. Balanced hydroxyethyl-starch solutions are also available today. All of these preparations are characterized by the presence of metabolizable organic anions such as lactate, acetate or malate and contain physiological electrolyte concentrations. Theoretically, balanced solutions which possess a strong ion difference (SID) of around 24 
mmol/L after metabolization (for example, Ringer's lactate) are supposed to have no influence on blood $\mathrm{pH}$ even after intravenous infusion of several liters [8]. However, balanced crystalloids containing lactate have some disadvantages as well [9]. Their metabolism depends on liver function and does require increased oxygen consumption. Acetated solutions do not display these shortcomings, but previous studies in patients undergoing hemodialysis have demonstrated that their administration may lead to hemodynamic instability and hypotension [10].

Despite their future perspective, to date the routine use of balanced crystalloids is still infrequent in anesthesia. Large randomized, controlled clinical trials (RCT's) investigating possible advantages as well as adverse effects of balanced crystalloids for routine use in the operating theater are sparse. The aim of the current study was to provide a preliminary comparison of two differently buffered balanced infusion solutions by reviewing data obtained from two established clinical protocols and,in addition, to test the feasibility of a future large RCT. The main target of interest was to investigate the influence of a solution containing a plasma-like SID (acetate buffered, SID $=36.8 \mathrm{mmol} / \mathrm{L}$ ) and a solution with a comparably low SID (lactate buffered, SID $=28 \mathrm{mmol} / \mathrm{L}$ ) on the variables of Stewart's acid-base approach including the effective strong ion difference (SIDe). The impact of the acetate-based infusion solution on hemodynamic stability was also studied. In order to guide a future RCT, primary and secondary variables of interest were determined and sample size estimation was performed.

\section{Methods}

In 2009 Ringer's lactate (B. Braun Melsungen, Melsungen, Germany) was replaced by Ionosteril ${ }^{\mathrm{TM}}$ (Fresenius Medical Care, Schweinfurt, Germany), an acetate-based infusion solution (ABIS), as a standard intraoperative infusion solution in our institution. In a before and after analysis we studied acid-base balance and hemodynamics in 24 women without obvious cardiac, pulmonary or renal diseases (classified as American Society of Anesthesiologists physical status I or II) who underwent major, open gynecologic cancer surgery. The study comprised two arms: the first consisted of patients who had received solely Ringer's lactate ( $\mathrm{RL}$-group, $\mathrm{n}=12$ ) and the second of women who were treated only with the ABIS (ABIS-group, $n=12$ ). The composition of both infusion solutions is listed in Table 1. Patients suffering from pre-existing acid-base disorders and patients who required blood transfusions, plasma products or colloids during the study period were not included in the investigation. A retrospective chart review was
Table 1 Composition of study solutions

\begin{tabular}{|c|c|c|}
\hline & Ringer's lactate & ABIS \\
\hline \multicolumn{3}{|c|}{$\mathrm{mmol} / \mathrm{L}$} \\
\hline$\left[\mathrm{Na}^{+}\right]$ & 131 & 137 \\
\hline$\left[\mathrm{Cl}^{-}\right]$ & 112 & 110 \\
\hline$\left[\mathrm{K}^{+}\right]$ & 5.4 & 4 \\
\hline$\left[\mathrm{Mg}^{++}\right]$ & 0 & 1.25 \\
\hline$\left[\mathrm{Ca}^{++}\right]$ & 1.8 & 1.65 \\
\hline [Lactate] & 28 & 0 \\
\hline [Acetate] & 0 & 36.8 \\
\hline Strong ion difference & 28 & 36.8 \\
\hline \multicolumn{3}{|c|}{ mosmol/L } \\
\hline Osmolarity (calculated) & 276 & 291 \\
\hline Osmolality (in vivo) & 256 & 270 \\
\hline
\end{tabular}

[, serum concentration of the ion between the brackets; ABIS, acetate-based infusion solution.

performed for patients in both arms. The mean intergroup difference of changes in SIDe between baseline values and the end of the study period was defined as the primary variable of interest. Changes in arterial plasma $\mathrm{pH}$ and noradrenalin requirements during general anesthesia were considered as secondary variables. The target parameters of the study were obtained from intraoperative routine blood samples, taken from arterial lines in patients requiring postoperative intensive care management (see Table 2). Because no additional blood sampling was necessary and the study was designed to evaluate two different versions of an established infusion regimen, the Ethics Committee of the University of Munich waived the need for patient's informed consent for this pilot trial.

General anesthesia was induced with intravenous propofol, sufentanil, and cis-atracurium. After tracheal intubation, anesthesia was maintained with propofol (6 to $10 \mathrm{mg} / \mathrm{kg} /$ hour) and additional doses of sufentanil and cis-atracurium as appropriate. Mechanical ventilation was performed to maintain an adequate oxygenation and to preserve normocapnia. Intraoperative monitoring included end-tidal $\mathrm{P}_{\mathrm{a}} \mathrm{CO}_{2}$, electrocardiography, central venous pressure, arterial blood pressure, pulseoximetry and esophageal temperature. During the operative period, the patient's temperature was kept constant in any case. Urinary output as well as the blood loss during the time course of the investigation was noted. In order to obtain blood $\mathrm{pH}$, base excess $(\mathrm{BE}), \mathrm{HCO}_{3}^{-}$and $\mathrm{P}_{\mathrm{a}} \mathrm{CO}_{2}$, a standard blood gas analyzer (Bayer Rapidlab 1265, Bayer Healthcare LLC, East Walpole, MA, USA) was used. Serum electrolyte and lactate concentrations, as well as hemoglobin, hematocrit and albumin concentrations were assessed in the central laboratory of our 
Table 2 List of variables

\begin{tabular}{|c|c|c|c|}
\hline & Measurement at: & & Measurement at: \\
\hline Hemodynamics & & Acid Base Balance & \\
\hline Noradrenalin requirement (mg/h) & $B L-T 120$ & Anion Gap (mmol/L) & $B L-T 120$ \\
\hline Heart rate (min-1) & $\mathrm{BL}-\mathrm{T} 120$ & HCO3- (mmol/L) & $\mathrm{BL}-\mathrm{T} 120$ \\
\hline ABP systolic (mmHg) & $\mathrm{BL}-\mathrm{T} 120$ & $\mathrm{BE}(\mathrm{mmol} / \mathrm{L})$ & $\mathrm{BL}-\mathrm{T} 120$ \\
\hline ABP diastolic (mmHg) & $\mathrm{BL}-\mathrm{T} 120$ & $\mathrm{pH}$ & $\mathrm{BL}-\mathrm{T} 120$ \\
\hline Central venous pressure $(\mathrm{mmHg})$ & $B L-T 120$ & $\mathrm{paCO} 2(\mathrm{mmHg})$ & $\mathrm{BL}-\mathrm{T} 120$ \\
\hline Blood loss (mL) & $\mathrm{BL}-\mathrm{T} 120$ & & \\
\hline Hemoglobin (g/dL) & $\mathrm{BL}-\mathrm{T} 120$ & Stewart Acid Base Approach $[\mathrm{A}-](\mathrm{mmol} / \mathrm{L})$ & $\mathrm{BL}-\mathrm{T} 120$ \\
\hline Hematocrit (\%) & $\mathrm{BL}-\mathrm{T} 120$ & Effective Strong Ion Difference (mmol/L) & $\mathrm{BL}-\mathrm{T} 120$ \\
\hline Urine quantity (mL) & $\mathrm{BL}-\mathrm{T} 120$ & Strong lon Gap (mmol/L) & $\mathrm{BL}-\mathrm{T} 120$ \\
\hline \multirow[t]{2}{*}{ Administered amount of RL/ABIS (mL) } & $\mathrm{BL}-\mathrm{T} 120$ & [Albumin] (g/L) & $\mathrm{BL}-\mathrm{T} 120$ \\
\hline & & [Serum-Lactate] (mmol/L) & $\mathrm{BL}-\mathrm{T} 120$ \\
\hline Serum-Electrolytes([Na+][Cl-] [K+] $[\mathrm{Mg}++][\mathrm{Ca}++])$ & $\mathrm{BL}-\mathrm{T} 120$ & {$[\mathrm{~A}-]:=$ Serum-concentration of week acids } & $\mathrm{BL}-\mathrm{T} 120$ \\
\hline
\end{tabular}

$\mathrm{ABIS}$, acetate-based infusion solution; $\mathrm{ABP}$, arterial blood pressure; $\mathrm{BE}$, base excess; $\mathrm{BL}$, baseline; [ , serum concentration of the variable between the brackets.

institution. Depending on the results of the laboratory measurements the following variables were calculated:

- $\left[\mathrm{PO}_{4}^{3-}\right]$ ionized $(\mathrm{Pi})(\mathrm{mmol} / \mathrm{L}):=\left[\mathrm{PO}_{4}^{3-}\right](\mathrm{mg} / \mathrm{dL})$. 0.3229

- Anion gap $(\mathrm{mmol} / \mathrm{L}):=\left[\mathrm{Na}^{+}\right]-\left[\mathrm{Cl}^{-}\right]-\left[\mathrm{HCO}_{3}^{-}\right]$

- Effective Strong Ion Difference $\left(\operatorname{SID}_{\mathrm{e}}\right)(\mathrm{mmol} / \mathrm{L}):=$ $[\mathrm{A}-]+\left[\mathrm{HCO}_{3}^{-}\right]=[\mathrm{A}-]+\left(0.0304 \cdot \mathrm{PCO}_{2} \cdot 10^{(\mathrm{pH}-6.1)}\right)$ according to Figge $[11,12]$

- Week acids serum-concentration $\left[\mathrm{A}^{-}\right](\mathrm{mmol} / \mathrm{L}):=$ [Albumin $\cdot(0.123 \cdot \mathrm{pH}-0.631)]+[\mathrm{Pi} \cdot(0.309 \cdot \mathrm{pH}-$ 0.469)] according to Figge $[11,12]$

- Strong Ion Gap (SIG) $(\mathrm{mmol} / \mathrm{L}):=\left[\mathrm{Na}^{+}\right]+\left[\mathrm{K}^{+}\right]+2$ $\left[\mathrm{Ca}^{++}\right]+2\left[\mathrm{Mg}^{++}\right]-\left[\mathrm{Cl}^{-}\right]-\left[\mathrm{Lac}^{-}\right]-\left[\mathrm{A}^{-}\right]-\left[\mathrm{HCO}_{3}^{-}\right]$ according to Stewart [13]

\section{Hemodynamics}

In accordance with our institution's clinical practice a mean arterial pressure (MAP) of at least $80 \mathrm{mmHg}$ was regarded as necessary during general anesthesia. If volume replacement with the study solutions alone (up to $30 \mathrm{ml} / \mathrm{kg}$ /hour) was not sufficient to maintain the necessary level of MAP norepinephrine was administered in increasing doses of $0.1 \mathrm{mg} /$ hour as required until the target value was achieved.

\section{Statistical analysis}

Mean, standard deviation of the mean (parametric values), median and range (non-parametric data) were calculated for each target parameter. The Shapiro-Wilk test was used to test for normality. Because most of the data were normally distributed, they are presented as mean \pm standard deviation. We used a repeated measurement analysis of variances (RM-ANOVA) followed by a Student-Newman-Keuls test (with data normally distributed) or a Friedman test (with data not normally distributed) to describe changes of measurement parameters within a group during the course of time (three points of measurement). In order to compare differences between the groups an ANOVA was followed by a Student-Newmann-Keuls test (see above). If data were not normally distributed a one-way ANOVA on ranks (Kruskal-Wallis test) was followed by Dunn's test. For all determinations a type I error protection of $P<0.05$ was considered significant. Statistical analysis was performed using Sigma Stat Software Version 3.1 (RockWare Inc. Golden, Colorado, USA) and Microsoft Excel Version 2003 (Microsoft Deutschland GmbH, Unterschleißheim, Germany). All electrolyte concentrations are expressed as mmolLl.

\section{Results}

We did not notice significant differences concerning patients' demographic data (mean age: RL-group, $64 \pm 8$; ABIS-group, $61 \pm 10$ years; mean body mass index: RLgroup, $24.8 \pm 2.6$; ABIS-group, $24.5 \pm 3.5$; mean body weight: RL-group, $68.6 \pm 6.0 \mathrm{~kg}$; ABIS-group, $66.4 \pm 14.0$ $\mathrm{kg})(P>0.05$ for all comparisons). All women underwent surgery for ovarian cancer including open radical hysterectomy, adnexal surgery and para-aortal as well as pelvic lymph node dissection. Twenty-four patients, who $a$ priori fulfilled the inclusion criteria, were enrolled in this study (12 per group). Protocol violations were not observed and subsequently there was no need to retrospectively exclude patients from the trial. The mean intergroup difference of changes in SIDe between BL and T120 proved to be $2.08 \pm 2.9 \mathrm{mmol} / \mathrm{L}$, indicating a strong effect $(\mathrm{d}=0.91)$ according to Cohen [14]. Thus, assuming an effect size of $2 \mathrm{mmol} / \mathrm{L}$, a future RCT 
should include at least 35 patients in each study group, given a type II error protection of $\beta>0.8$.

\section{Acid-base balance and Stewart approach}

Parameters contributing to the 'classic' acid-base balance (see Table 3) did not differ significantly between groups at any time point of measurement. Intergroup comparisons concerning parameters relevant for Stewart's acid-base approach, especially the SIDe, showed no significant differences, either. However, values noticed for the RL-group showed small but significant intragroup changes during the time course, especially concerning $\mathrm{pH}$ and $\left[\mathrm{HCO}_{3}^{-}\right]$. In the ABIS-group, these values did not change. In addition, relevant intragroup reductions were observed in $\mathrm{SID}_{\mathrm{e}}$ and [A $\mathrm{A}^{-}$for RL and ABIS. Albumin serum concentrations were diminished to approximately $80 \%$ of their basic values in both groups.

\section{Hemodynamics}

The overall mean blood loss during the time course was $763 \pm 427 \mathrm{ml}$; it was $655 \pm 460 \mathrm{ml}$ in the RL-group and $870 \pm 378 \mathrm{ml}$ in the ABIS-group $(P>0.05)$. The total amount of the infused study solutions was 4,066 \pm 308 $\mathrm{ml}$ for $\mathrm{RL}$ and $4,041 \pm 572 \mathrm{ml}$ for the ABIS $(P>0.05)$. Norepinephrine requirements increased constantly during the study period, but differences between groups did not reach significance. Nevertheless, a slight but significant reduction in CVP could be observed in the RL- group. There were no differences in urine output. Further parameters listed under 'Hemodynamics' in Table 4 were not significantly different between groups.

\section{Electrolytes}

Serum electrolytes were measured mainly to calculate the parameters of the Stewart approach. Except for [lactate $]$ and $\left[\mathrm{Mg}^{++}\right]$no significant differences between the study groups were observed (see Table 5 ). Significantly higher levels of $\left[\mathrm{Mg}^{++}\right]$could be found in the ABISgroup at T60 and T120. Serum lactate concentrations were significantly elevated for RL compared to ABIS at $\mathrm{T} 60$ and $\mathrm{T} 120 \quad(P<0.05$ for all comparisons $)$. In addition, a significant increase in $\left.\mathrm{Cl}^{-}\right]$could be noticed during the time course in the RL-group (Table 5), but not in the ABIS-group.

\section{Discussion}

The current investigation was designed to compare two currently available balanced infusion solutions in a clinical setting. One solution contained lactate, the other acetate as a metabolizable anion. Main areas of interest were the influence of these solutions on acid-base balance and hemodynamic stability.

\section{Acid-base balance}

On first sight, the acid-base parameters $\mathrm{pH}, \mathrm{BE}$ and $\left[\mathrm{HCO}_{3}^{-}\right]$remained remarkably constant during the time

Table 3 Acid-base parameters

\begin{tabular}{|c|c|c|c|c|c|c|c|c|}
\hline & & \multicolumn{2}{|c|}{ BL } & \multicolumn{2}{|c|}{$\mathrm{T} 60$} & \multicolumn{2}{|c|}{$\mathrm{T} 120$} & \multirow{2}{*}{$\frac{\mathrm{I} \Delta 120 \mathrm{I}}{\text { Mean } \pm \mathrm{SD}}$} \\
\hline & & Mean \pm SD & $95 \% \mathrm{Cl}$ & Mean \pm SD & $95 \% \mathrm{Cl}$ & Mean \pm SD & $95 \% \mathrm{Cl}$ & \\
\hline \multirow[t]{2}{*}[\mathrm{HCO}_{3}^{-}]{} & $\mathrm{RL}^{*}$ & $24.65 \pm 2.69$ & $(22.94-26.36)$ & $23.86 \pm 2.86$ & $(22.04-25.68)$ & $23.41 \pm 3.62$ & $(21.11-25.71)$ & $1.24 \pm 1.72$ \\
\hline & ABIS & $25.09 \pm 2.52$ & $(23.49-26.69)$ & $25.19 \pm 1.85$ & $(24.01-26.37)$ & $24.53 \pm 2.31$ & $(23.06-26.00)$ & $0.56 \pm 1.79$ \\
\hline \multirow[t]{2}{*}{ BE } & $\mathrm{RL}^{*}$ & $0.38 \pm 2.89$ & $(-1.46-2.22)$ & $-1.11 \pm 3.3$ & $(-3.21-0.99)$ & $-1.63 \pm 3.63$ & $(-3.94-0.68)$ & $2.0 \pm 1.87$ \\
\hline & ABIS & $0.48 \pm 2.63$ & $(-1.19-2.15)$ & $0.45 \pm 1.99$ & $(-0.81-1.71)$ & $-0.07 \pm 2.51$ & $(-1.66-1.52)$ & $0.54 \pm 1.46$ \\
\hline \multirow[t]{2}{*}{$\mathrm{pH}$} & $\mathrm{RL}^{*}$ & $7.42 \pm 0.05$ & $(7.39-7.45)$ & $7.39 \pm 0.04$ & $(7.36-7.42)$ & $7.37 \pm 0.03$ & (7.35-7.39) & $0.05 \pm 0.02$ \\
\hline & ABIS & $7.41 \pm 0.03$ & $(7.39-7.43)$ & $7.42 \pm 0.04$ & (7.39-7.45) & $7.39 \pm 0.04$ & $(7.36-7.42)$ & $0.03 \pm 0.03$ \\
\hline \multirow[t]{2}{*}{$\mathrm{p}_{\mathrm{a}} \mathrm{CO}_{2}(\mathrm{mmHg})$} & RL & $39.56 \pm 1.5$ & $(38.61-40.51)$ & $39.58 \pm 1.46$ & $(38.65-40.51)$ & $40.73 \pm 3.04$ & $(38.80-42.66)$ & $1.16 \pm 2.69$ \\
\hline & ABIS & $40.35 \pm 2.77$ & $(38.59-42.11)$ & $40.55 \pm 2.85$ & $(38.74-42.36)$ & $40.95 \pm 1.87$ & $(39.76-42.14)$ & $0.6 \pm 2.40$ \\
\hline \multirow[t]{2}{*}[\mathrm{A}^{-}]{} & $\mathrm{RL}^{*}$ & $12.51 \pm 1.2$ & $(11.75-13.27)$ & $10.52 \pm 1.05$ & $(9.85-11.19)$ & $9.81 \pm 2.0$ & (8.54-11.08) & $2.69 \pm 1.70$ \\
\hline & $\mathrm{ABIS}^{*}$ & $12.80 \pm 2.35$ & $(11.31-14.29)$ & $10.12 \pm 1.39$ & (9.24-11.00) & $10.12 \pm 1.82$ & $(8.96-11.28)$ & $2.67 \pm 2.40$ \\
\hline \multirow[t]{2}{*}{$\mathrm{SID}_{\mathrm{e}}$} & $\mathrm{RL}^{*}$ & $37.90 \pm 3.75$ & $(35.52-40.28)$ & $34.34 \pm 3.19$ & $(32.31-36.37)$ & $33.20 \pm 4.81$ & $(30.16-36.28)$ & $4.71 \pm 2.71$ \\
\hline & $\mathrm{ABIS}^{*}$ & $37.45 \pm 3.00$ & $(35.54-39.36)$ & $35.34 \pm 2.50$ & $(33.75-36.93)$ & $34.82 \pm 4.00$ & $(32.28-37.36)$ & $2.63 \pm 1.75$ \\
\hline \multirow[t]{2}{*}{ SIG } & $\mathrm{RL}^{*}$ & $4.95 \pm 3.38$ & $(2.80-7.10)$ & $1.67 \pm 3.03$ & $(-0.26-3.60)$ & $0.73 \pm 4.43$ & $(-2.08-3.54)$ & $4.21 \pm 2.93$ \\
\hline & $\mathrm{ABIS}^{\circ}$ & $2.98 \pm 2.31$ & $(1.51-4.45)$ & $1.56 \pm 1.0$ & $(0.92-2.20)$ & $2.44 \pm 1.99$ & $(1.18-3.70)$ & $0.54 \pm 2.76$ \\
\hline \multirow[t]{2}{*}{ Albumin[g/l] } & $\mathrm{RL}^{*}$ & $37.0 \pm 4.31$ & $(34.26-39.74)$ & $30.58 \pm 3.68$ & $(28.24-32.92)$ & $28.41 \pm 6.91$ & $(24.02-32.80)$ & $8.60 \pm 5.71$ \\
\hline & $A B I S^{*}$ & $35.82 \pm 7.70$ & (30.93-40.71) & $29.18 \pm 4.21$ & $(26.51-31.85)$ & $29.10 \pm 5.58$ & $(25.55-32.65)$ & $6.72 \pm 8.45$ \\
\hline
\end{tabular}

All values except $\mathrm{p}_{2} \mathrm{CO}_{2}$, albumin and $\mathrm{pH}$ are given in $\mathrm{mmol} / \mathrm{L}$. ABIS, acetate-based infusion solution; $\mathrm{BE}$, base excess; $\mathrm{BL}$, baseline measurement; $\mathrm{RL}$, Ringer's lactate; SD, standard deviation; SIDe, effective strong ion difference; SIG, strong ion gap; T60, T120, measurement at $60 \pm 10$ and $120 \pm 10$ minutes; $95 \% \mathrm{Cl}, 95 \%$ confidence interval of means; I $\Delta 120 \mathrm{I}$, absolute value of the difference between T120 and baseline measurements. *, Significant intragroup changes over time $(P<0.05)$ between $\mathrm{BL}$ and $\mathrm{T} 120 ;{ }^{\circ}$, Significant intragroup changes over time $(P<0.05)$ between $\mathrm{BL}$ and T60. 
Table 4 Hemodynamics

\begin{tabular}{|c|c|c|c|c|c|c|c|c|}
\hline & & \multicolumn{2}{|c|}{$\mathrm{BL}$} & \multicolumn{2}{|c|}{ T60 } & \multicolumn{2}{|c|}{ T120 } & \multirow{2}{*}{$\frac{\mathrm{I} \Delta 120 \mathrm{I}}{\text { Mean } \pm \text { SD }}$} \\
\hline & & Mean \pm SD & $95 \% \mathrm{Cl}$ & Mean \pm SD & $95 \% \mathrm{Cl}$ & Mean \pm SD & $95 \% \mathrm{Cl}$ & \\
\hline \multirow[t]{2}{*}{ Norepinephrine requirements (mg/hour) } & $R L^{*}$ & $0.1 \pm 0.1$ & $(0.04-0.16)$ & $0.3 \pm 0.2$ & $(0.17-0.43)$ & $0.4 \pm 0.3$ & $(0.21-0.59)$ & $0.3 \pm 0.3$ \\
\hline & $A B \mid S^{*}$ & $0.1 \pm 0.1$ & $(0.04-0.16)$ & $0.3 \pm 0.2$ & $(0.17-0.43)$ & $0.5 \pm 0.4$ & $(0.25-0.75)$ & $0.41 \pm 0.4$ \\
\hline \multirow[t]{2}{*}{ Urine-Quantity (ml) } & $R L^{*}$ & $8.3 \pm 19.4$ & $(-4.03-20.63)$ & $210.8 \pm 165.2$ & $(105.84-315.76)$ & $630.8 \pm 422.2$ & $(362.5-899.0)$ & $622.5 \pm 404.4$ \\
\hline & $\mathrm{ABIS}^{*}$ & $15.8 \pm 31.7$ & $(-4.34-35.94)$ & $216.6 \pm 153.3$ & $(119.20-314.00)$ & $533.3 \pm 286.2$ & $(351.4-715.1)$ & $517.5 \pm 271.6$ \\
\hline \multirow[t]{2}{*}{$\mathrm{HR}\left(\min ^{-1}\right)$} & $\mathrm{RL}$ & $55.2 \pm 10.9$ & $(48.27-62.13)$ & $56.1 \pm 11.8$ & $(48.60-63.60)$ & $58.7 \pm 13.6$ & $(50.06-67.34)$ & $3.5 \pm 5.3$ \\
\hline & ABIS & $55.0 \pm 6.3$ & $(51.00-59.00)$ & $60.8 \pm 10.4$ & $(54.19-67.41)$ & $59.9 \pm 13.9$ & $(51.07-68.73)$ & $4.9 \pm 10.0$ \\
\hline \multirow[t]{2}{*}{ MAP mmHg) } & $\mathrm{RL}$ & $86.4 \pm 8.9$ & (80.75-92.05) & $85.5 \pm 11.7$ & (78.07-92.93) & $84.4 \pm 11.5$ & $(77.09-91.71)$ & $2.0 \pm 11.2$ \\
\hline & ABIS & $88.9 \pm 13.3$ & $(80.45-97.35)$ & $94.1 \pm 15.7$ & (84.12-104.08) & $91.3 \pm 15.0$ & $(81.77-100.83)$ & $2.4 \pm 14.8$ \\
\hline \multirow[t]{2}{*}{ CVP $(\mathrm{mmHg})$} & $\mathrm{RL}^{*}$ & $11.2 \pm 2.3$ & $(9.74-12.66)$ & $10.7 \pm 3.5$ & $(8.48-12.92)$ & $8.8 \pm 3.5$ & $(6.58-11.02)$ & $2.4 \pm 3.4$ \\
\hline & ABIS & $10.9 \pm 3.2$ & $(8.87-12.93)$ & $12.7 \pm 5.3$ & $(9.33-16.07)$ & $11.4 \pm 4.4$ & $(8.60-14.20)$ & $0.57 \pm 5.4$ \\
\hline
\end{tabular}

ABIS, acetate-based infusion solution; $B L$, baseline measurement; $C V P$, central venous pressure; $H R$, heart rate; $M A P$, mean arterial pressure; $R L$, Ringer's lactate; $S D$, standard deviation; T60, T120, measurement at $60 \pm 10$ and $120 \pm 10$ minutes; $95 \% \mathrm{Cl}, 95 \%$ confidence interval of means; I $\Delta 120 \mathrm{I}$, absolute value of the difference between T120 and baseline measurements; ${ }^{*}$, significant intragroup changes over time $(P<0.05)$ between BL and T120.

course. This observation corresponds to the results of previous investigators $[4,8]$. However, it was evident that the ABIS had less influence on the 'classic' acid-base parameters than RL. $\mathrm{pH},\left[\mathrm{HCO}_{3}^{-}\right]$and $\mathrm{BE}$ did not change from BL to T120 in the ABIS-group, whereas a small but significant reduction of $\mathrm{pH}$ values and $\left[\mathrm{HCO}_{3}^{-}\right]$could be observed in the RL-group. Concerning the parameters of Stewart's acid-base model, we noticed a relevant reduction in serum albumin concentrations, which is easily explained by the diluting effects of the albumin-free crystalloid solutions. This reduction was accompanied by a corresponding decrease in $\left[\mathrm{A}^{-}\right](\Delta \mathrm{BL}-$ T120: RL-group, $2.70 \mathrm{mmol} / \mathrm{L}$; ABIS-group, $2.68 \mathrm{mmol} / \mathrm{L}$ ). In addition, the $\mathrm{SID}_{\mathrm{e}}$ declined as well. In contrast to $\left[\mathrm{A}^{-}\right] \mathrm{a}$ small difference in the quantity of the decline could be observed with $\operatorname{SID}_{\mathrm{e}}(\Delta \mathrm{BL}-\mathrm{T} 120$ : RL-group, $4.7 \mathrm{mmol} / \mathrm{l}$; ABIS-group, $2.6 \mathrm{mmol} / \mathrm{L} ; P>0.05)$. Although the difference in $\mathrm{SID}_{\mathrm{e}}$-reduction was not significant between groups, one can speculate that the pronounced decrease of effective SID in the RL-group (which should lead to an acidosis according to the Stewart approach) was only incompletely neutralized by the decrease in $\left[\mathrm{A}^{-}\right]$(which

Table 5 Serum electrolyte concentrations

\begin{tabular}{|c|c|c|c|c|c|c|c|c|}
\hline & & \multicolumn{2}{|c|}{$\mathrm{BL}$} & \multicolumn{2}{|c|}{ T60 } & \multicolumn{2}{|c|}{$\mathrm{T} 120$} & \multirow{2}{*}{$\frac{\mathrm{I} \Delta 120 \mathrm{I}}{\text { Mean } \pm \text { SD }}$} \\
\hline & & Mean \pm SD & $95 \% \mathrm{Cl}$ & Mean \pm SD & $95 \% \mathrm{Cl}$ & Mean \pm SD & $95 \% \mathrm{Cl}$ & \\
\hline \multirow[t]{2}{*}[\mathrm{Na}^{+}]{} & $R L^{*}$ & $137.3 \pm 4.8$ & $(134.2-140.4)$ & $136.2 \pm 4.7$ & $(133.2-139.2)$ & $135.8 \pm 5.1$ & $(132.5-139.0)$ & $1.52 \pm 1.65$ \\
\hline & ABIS & $138.9 \pm 2.5$ & (137.3-140.5) & $138.3 \pm 2.3$ & $(136.8-139.7)$ & $138.5 \pm 2.7$ & $(136.8-140.2)$ & $0.35 \pm 2.9$ \\
\hline \multirow[t]{2}{*}[\mathrm{K}^{+}]{} & $\mathrm{RL}^{*}$ & $3.5 \pm 0.2$ & $(3.4-3.7)$ & $3.6 \pm 0.3$ & $(3.40-3.79)$ & $3.7 \pm 0.5$ & $(3.38-4.01)$ & $0.26 \pm 0.52$ \\
\hline & $A B \mid S^{*}$ & $3.5 \pm 0.3$ & $(3.31-3.70)$ & $3.7 \pm 0.3$ & $(3.50-3.89)$ & $3.7 \pm 0.2$ & $(3.57-3.82)$ & $0.22 \pm 0.31$ \\
\hline \multirow[t]{2}{*}[\mathrm{Cl}^{-}]{} & $\mathrm{RL}^{*}$ & $101.8 \pm 5.4$ & (99.0-104.8) & $105.8 \pm 5.0$ & $(102.6-109.0)$ & $107.5 \pm 4.6$ & $(104.6-110.4)$ & $5.60 \pm 2.4$ \\
\hline & ABIS & $105.5 \pm 3.3$ & (103.4-107.6) & $108.4 \pm 2.5$ & $(106.8-110.0)$ & $108.6 \pm 2.2$ & $(107.2-110.0)$ & $3.08 \pm 1.46$ \\
\hline \multirow[t]{2}{*}[\mathrm{Mg}^{2+}]{} & $\mathrm{RL}^{*}$ & $0.77 \pm 0.1$ & $(0.71-0.82)$ & $0.69 \pm 0.1 \#$ & $(0.62-0.75)$ & $0.66 \pm 0.1 \#$ & $(0.59-0.72)$ & $0.11 \pm 0.12$ \\
\hline & ABIS & $0.83 \pm 0.06$ & $(0.79-0.87)$ & $0.85 \pm 0.04 \#$ & $(0.82-0.87)$ & $0.87 \pm 0.04 \#$ & $(0.84-0.89)$ & $0.04 \pm 0.06$ \\
\hline \multirow[t]{2}{*}[\mathrm{Ca}^{2+}]{} & $\mathrm{RL}$ & $1.16 \pm 0.04$ & $(1.13-1.19)$ & $1.16 \pm 0.04$ & $(1.13-1.18)$ & $1.16 \pm 0.02$ & $(1.14-1.17)$ & $0.00 \pm 0.03$ \\
\hline & ABIS & $1.17 \pm 0.03$ & $(1.15-1.19)$ & $1.16 \pm 0.03$ & $(1.14-1.18)$ & $1.16 \pm 0.03$ & $(1.14-1.17)$ & $0.01 \pm 0.02$ \\
\hline \multirow[t]{2}{*}{ [Lac'] } & $\mathrm{RL}^{*}$ & $0.8 \pm 0.3$ & $(0.66-1.07)$ & $1.6 \pm 0.6 \#$ & $(1.21-1.98)$ & $1.9 \pm 0.7 \#$ & $(1.45-2.34)$ & $0.94 \pm 0.69$ \\
\hline & ABIS & $0.9 \pm 0.4$ & $(0.64-1.15)$ & $0.8 \pm 0.3 \#$ & $(0.60-1.0)$ & $0.8 \pm 0.2 \#$ & $(0.67-0.92)$ & $0.12 \pm 0.22$ \\
\hline$\left[\mathrm{PO}_{4}^{3-}\right]$ & $\mathrm{RL}$ & $3.5 \pm 0.4$ & $(3.21-3.78)$ & $3.4 \pm 0.4$ & $(3.14-3.65)$ & $3.3 \pm 0.4$ & $(3.04-3.55)$ & $0.19 \pm 0.32$ \\
\hline$(\mathrm{mg} / \mathrm{dL})$ & ABIS & $3.4 \pm 0.5$ & (3.08-3.719 & $3.3 \pm 0.5$ & $(3.00-3.60)$ & $3.4 \pm 0.6$ & $(3.02-3.78)$ & $0.01 \pm 0.28$ \\
\hline
\end{tabular}

All values except $\left[\mathrm{PO}_{4}^{3-}\right]$ are given in $\mathrm{mmol} / \mathrm{L}$. ABIS, acetate-based infusion solution; $\mathrm{BL}$, baseline measurement; $\mathrm{RL}$, Ringer's lactate; $\mathrm{SD}$, standard deviation; $\mathrm{T} 60$, T120, measurement at $60 \pm 10$ and $120 \pm 10$ minutes; $95 \% \mathrm{Cl}, 95 \%$ confidence interval of means; I $\Delta 120 \mathrm{I}$, absolute value of the difference between T120 and baseline measurements; ${ }^{*}$, significant intragroup changes over time $(P<0.05)$ between $\mathrm{BL}$ and T120; \#, significant differences between groups at the referring time points of measurement $(P<0.05)$. 


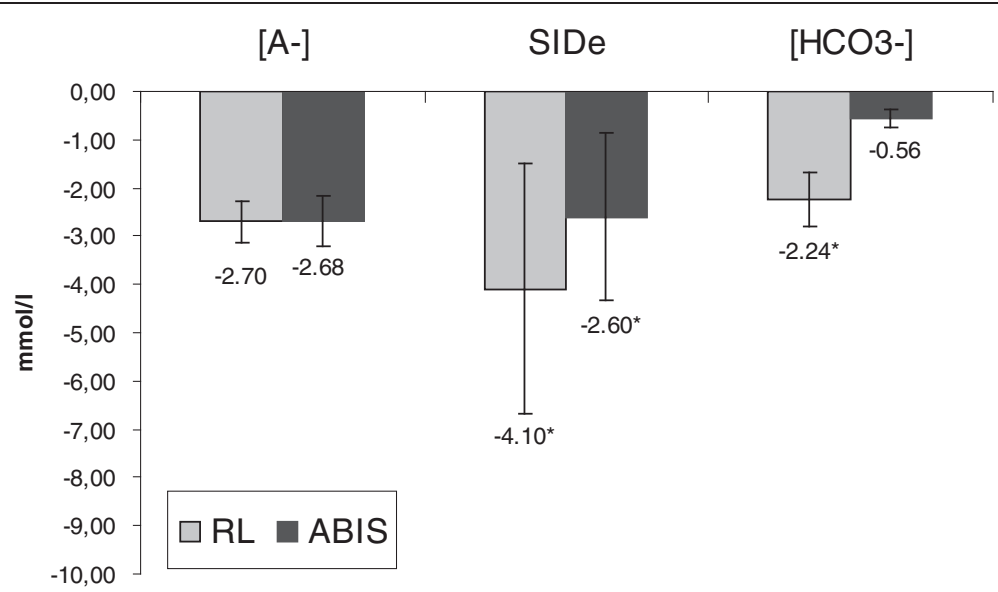

Figure 1 Reduction of $\left[\mathrm{A}^{-}\right], \mathrm{SID}_{\mathrm{e}}$ and $\left[\mathrm{HCO}_{3}^{-}\right]$during the time course (BL - T120). ABIS, acetate-based infusion solution; $B \mathrm{~L}$, baseline; $\mathrm{RL}$, Ringer's lactate; T120, measurement at $120 \pm$ minutes; $\mathrm{SID}_{\mathrm{e}}$, effective strong ion difference; ${ }^{*}$, significant intragroup changes over time $(P<0.05)$ between BL and T120.

should lead to an alkalosis). This might explain the small but significant $\mathrm{pH}$ reduction that could be observed in the RL-group (see Figure 1).

This finding is surprising, because it does not correspond to Morgan's theory of the 'ideal SID' [7]. According to Morgan et al. only infusion solutions with a SID of around $24 \mathrm{mmol} / \mathrm{L}$ do not influence blood $\mathrm{pH}$. As a consequence one should have expected RL (SID $28 \mathrm{mmol} /$ L) rather than ABIS (SID $36.8 \mathrm{mmol} / \mathrm{L}$ ) to guarantee $\mathrm{pH}$ stability and ABIS to cause a mild alkalosis. Nevertheless, in the current study ABIS, whose SID nearly approximates normal plasma $\operatorname{SID}_{\mathrm{e}}(39 \pm 4 \mathrm{mmol} / \mathrm{L})$, provided better $\mathrm{pH}$ stability [15]. We have no explanation for the discrepancy concerning Morgan's theory. One can only speculate that perhaps infusion rate and/or metabolic turnover of the metabolizable anions may be important in this situation. In addition, according to Wooten's multi-compartmental model, not only extracellular, but also intracellular effects, and fluid redistribution between compartments may have influenced acid-base chemistry [16].

One possible limitation of the current study was that some of the values (especially the SID) had to be calculated from directly measured parameters. With differences between and within groups being very small, a propagation of errors could have influenced group comparisons. However, modern blood gas analyzers, as used in the current study, are able to measure acid-base variables extremely precisely ( $\mathrm{pH}$ bias $<0.005, \mathrm{PaCO}_{2}$ bias $<1.2 \mathrm{mmHg}$ ) [17]. In addition, measurement errors concerning the components of SID should occur similarly in all patients. Therefore, differences between groups should not be affected.

In summary, there were no significant intergroup differences to observe. Compared to RL, ABIS showed less influence on the 'classic' acid-base parameters $(\mathrm{pH}, \mathrm{BE}$, $\left.\left[\mathrm{HCO}_{3}^{-}\right]\right)$and the solution did not provoke a clinically relevant change in plasma $\operatorname{SID}_{\mathrm{e}}$. These results are in accordance with a recently published investigation on trauma patients requiring intensive care treatment with regard to $\mathrm{pH}$ stability provided by acetated solutions [18]. The clinical relevance of the relatively small intragroup changes in this study may be a matter of discussion. Scientific research on hyperchloremic acidosis has revealed that even small changes in $\mathrm{pH}$ can have a negative impact on various organ systems $[1,2,4,19]$. In addition, fluid requirements during major surgery may exceed by far the amount of four liters of crystalloids administered during the current study. Thus, small (but significant) differences concerning acid-base stability of applied crystalloids may gain importance successively if increasing amounts of fluids are administered.

\section{Hemodynamic values}

Hemodialysis with acetate-containing solutions can be the cause of severe hemodynamic instability because of increased nitric oxide synthesis and enhanced arrhythmias [20-22]. Even the small quantity of acetate present in various dialysis fluids (usually $35 \mathrm{mmol} / \mathrm{L}$ ) exposes a patient's blood to an acetate concentration 10 to 40 times the physiological level (50 to $100 \mu \mathrm{mol} / \mathrm{L}$ ) [23-25]. Fournier et al. observed that, according to the nature of hemodialysis (counter current process), the concentration of plasma acetate increased from $0.02 \mathrm{mmol} / \mathrm{L}$ to $0.22 \mathrm{mmol} / \mathrm{L}$ in three hours of hemodialysis [25]. To date, it is unknown whether the administration of acetated infusion solutions can provoke substantial rises in plasma acetate levels as well. However, one can speculate that while (slowly) infusing acetate-containing solutions, a considerably greater amount of the substance 
(compared to hemodialysis) will be metabolized. This should lead to relatively low serum concentrations.

This assumption is supported by two different observations: Firstly, no significant differences could be observed in terms of hemodynamic values between the study groups. Secondly, the SIG in the ABIS-group did not change significantly during the time course. According to Stewart's approach, an increase in plasma acetate must lead to an increase in SIG [13]. This hypothesis has been confirmed by Bruegger et al. in a hemorrhagic shock canine model: A $2.2 \mathrm{mmol} / \mathrm{L}$ rise in acetate plasma levels caused an identical (absolute) increase in SIG [26]. As a consequence, it is unlikely that relevant amounts of acetate accumulated in the circulation in the ABIS-group. However, hemodynamic stability could only be maintained by administering increasing amounts of norepinephrine ( $P<0.05$ from BL to T120 in both of the groups). There are several possible explanations: Firstly, the range of blood loss was relatively broad (from $50 \mathrm{ml}$ up to $1,500 \mathrm{ml}$ ). Despite fluid replacement, which, according to the literature, should have been adequate, these fluid losses were obviously not sufficiently counterbalanced in some of the patients, especially in the ABIS-group [27,28]. It seems probable that some patients developed a mild hypovolemia during the time course of the study. This assumption is supported by a decreasing CVP in the ABIS group, in which blood loss tended to be more severe than in the RL-group. Secondly, one has to take into account the mild vasodilatory effect of the used narcotics (propofol) that may have contributed to norepinephrine requirements. Thus, when considering only the current, preliminary data it seems that both solutions 'behaved like normal crystalloids' without substance-specific hemodynamic effects. However, it will be interesting to investigate if small intergroup differences observed for CVP or MAP which, nevertheless, are of clinical importance, will gain significance in a larger RCT.

\section{Additional findings}

Slightly elevated lactate levels were observed in the RLgroup. These increases were only moderate (but significant) and hardly exceeded our institutions' range of normal values ( 0.5 to $1.5 \mathrm{mmol} / \mathrm{L}$ ). In contrast to ABIS $\left[\mathrm{Mg}^{++}\right]$significantly decreased in the RL-group. Because RL does not contain magnesium, this can best be explained by a simple dilution effect. We consider these changes to be of minor clinical importance. However, for patients suffering from liver or metabolic diseases or cardiac arrhythmias ABIS might be the preferable infusion solution.

\section{Feasibility of a future RCT}

The current study showed that a larger RCT is feasible. The preliminary sample size estimation did not include the possibility of protocol violations or dropouts. Therefore, at least 35 patients will have to be enrolled in each group. With regard to the consistency of the study population in terms of co-factors of surgery and demographic data it is likely that a large RCT will provide reliable and reproducible results, despite the small intergroup differences in primary and secondary values of interest we observed.

\section{Conclusions}

In the current preliminary comparison Ringer's lactate as well as ABIS proved to be suitable for fluid replacement during abdominal surgery. Hemodynamic stability remained unaffected by both of the solutions. Concerning consistency of acid base parameters none of the solutions seemed to be clearly inferior, either. ABIS had a smaller effect on $\mathrm{pH}, \mathrm{BE},[\mathrm{HCO} 3-]$ and SIDe changes than lactated Ringer, but whether these differences will turn out to be of clinical relevance has to be investigated in a larger RCT. With regard to SIDe and [A-] neither ABIS nor Ringer's lactate seem to be 'ideally balanced', because both of these values decreased dose dependently in both groups. A future RCT might provide important data concerning the on-going search for an ideal balanced solution.

\section{Abbreviations}

[: serum-concentration of the ion between the brackets; [A-]: serumconcentration of week acids; ABIS: acetate-based infusion solution; $\mathrm{ABP}$ : arterial blood pressure; $\mathrm{BE}$ : base excess; $\mathrm{CVP}$ : central venous pressure; HR: heart rate; MAP: mean arterial pressure; $\mathrm{Pi}\left[\mathrm{PO}_{4}^{3-}\right]$ ionized; RCT: randomized controlled trial; RL: Ringer's lactate; SID: strong ion difference; SIDe: effective strong ion difference; SIG: strong ion gap.

\section{Competing interests}

This study was performed using research funding provided by Fresenius Medical Care (Fresenius Medical Care Deutschland GmbH, Hafenstr. 9, 97424 Schweinfurt, Bayern, Germany). Fresenius Medical Care did not have any influence on study design or manuscript approval. Klaus Hofmann-Kiefer, Matthias Jacob and Markus Rehm have lectured for Baxter Deutschland GmbH (Unterschleißheim, Germany), Fresenius Kabi Deutschland GmbH (Bad Homburg, Germany), B Braun, Melsungen AG (Melsungen, Germany), Serumwerk Bernburg AG (Bernburg, Germany) and CSL Behring GmbH (Marburg, Germany). In addition, they received unrestricted research grants from Serumwerk Bernburg AG (Bernburg, Germany), CSL Behring GmbH (Marburg, Germany) and Fresenius Kabi Deutschland GmbH (Bad Homburg, Germany). All authors declare they have no competing interests.

\section{Authors' contributions}

$\mathrm{KH}-\mathrm{K}$ made substantial contributions to the development of the study design, wrote the manuscript and performed the statistics. DC participated in data acquisition and analysis and critically revised the manuscript. TK and MP participated in data acquisition and patient coordination. MJ and PC critically revised and helped to draft the manuscript. MR participated substantially in the design and coordination of the study and gave final approval of the version to be published. All authors read and approved the final manuscript.

\section{Acknowledgements}

We thank Dr. J. Peters and Dr. N. Kohls for revising the statistics section of the manuscript and Prof. R. Mueller for correcting spelling and grammar. 
Received: 28 December 2011 Accepted: 4 June 2012

Published: 6 July 2012

\section{References}

1. Kellum JA, Song M, Venkataraman R: Effects of hyperchloremic acidosis on arterial pressure and circulating inflammatory molecules in experimental sepsis. Chest 2004, 125:243-248.

2. Kellum JA, Song M, Li J: Lactic and hydrochloric acids induce different patterns of inflammatory response in LPS-stimulated RAW 264.7 cells. Am J Physiol Regul Integr Comp Physiol 2004, 286:R686-R692.

3. Kellum JA: Metabolic acidosis in the critically ill: lessons from physical chemistry. Kidney Int Supp/ 1998, 66:S81-S86.

4. Wilkes NJ, Woolf R, Mutch M, Mallett SV, Peachey T, Stephens R, Mythen MG: The effects of balanced versus saline-based hetastarch and crystalloid solutions on acid-base and electrolyte status and gastric mucosal perfusion in elderly surgical patients. Anesth Analg 2001, 93:811-816.

5. Kellum JA: Clinical review: reunification of acid-base physiology. Crit Care 2005, 9:500-507

6. Kellum JA: Saline-induced hyperchloremic metabolic acidosis. Crit Care Med 2002, 30:259-261.

7. Morgan TJ, Venkatesh B: Designing 'balanced' crystalloids. Crit Care ResusC 2003, 5:284-291.

8. Scheingraber S, Rehm M, Sehmisch C, Finsterer U: Rapid saline infusion produces hyperchloremic acidosis in patients undergoing gynecologic surgery. Anesthesiology 1999, 90:1265-1270.

9. Guidet B, Soni N, Della RG, Kozek S, Vallet B, Annane D, James M: A balanced view of balanced solutions. Crit Care 2010, 14:325.

10. Bruges M, Barata JD, Oliveira C, Furstenau C, Gomes EM, Simoes J: Hemodialysis with bicarbonate $30 \mathrm{mEq} / \mathrm{l}$ versus $34 \mathrm{mEq} / \mathrm{l}$ and acetate: better hemodynamic tolerance and electrolyte and acid-base homeostasis. Acta Med Port 1994, 7:165-170.

11. Figge J, Mydosh T, Fend V: Serum proteins and acid-base equilibria: a follow-up. J Lab Clin Med 1992, 120:713-719.

12. Figge J, Rossing $\mathrm{TH}$, Fencl $\mathrm{V}$ : The role of serum proteins in acid-base equilibria. J Lab Clin Med 1991, 117:453-467.

13. Stewart PA: Modern quantitative acid-base chemistry. Can J Physiol Pharmacol 1983, 61:1444-1461.

14. Cohen J: Statistical Power Analysis for the Behavioral Sciences. 2nd edition. Hillsdale: Lawrence Erlbaum Associates; 1988:76-84.

15. Hofmann-Kiefer K, Conzen P, Rehm M: In Säure-Basen Status. In Die Intensivmedizin. 10th edition. Edited by Buchardi H, Larsen R, Kuhlen KW, Schölmerich J, Jauch KW. Heidelberg: Springer; 2008:744-753.

16. Wooten EW: Calculation of physiological acid-base parameters in multicompartment systems with application to human blood. J App/ Physiol 2003, 95:2333-2344.

17. Wahr JA, Lau W, Tremper KK, Hallock L, Smith K: Accuracy and precision of a new, portable, handheld blood gas analyzer, the IRMA 1. J Clin Monit 1996, 12::317-324.

18. McCague A, Dermendjieva M, Hutchinson R, Wong DT, Dao N: Sodium acetate infusion in critically ill trauma patients for hyperchloremic acidosis. Scand J Trauma Resusc Emerg Med 2011, 19:24.

19. Kellum JA: Fluid resuscitation and hyperchloremic acidosis in experimental sepsis: improved short-term survival and acid-base balance with Hextend compared with saline. Crit Care Med 2002, 30:300-305.

20. Santoro A, Guarnieri F, Ferramosca E, Grandi F: Acetate-free biofiltration. Contrib Nephrol 2007, 158:138-152.

21. Amore A, Cirina P, Mitola S, Peruzzi L, Bonaudo R, Gianoglio B, Coppo R: Acetate intolerance is mediated by enhanced synthesis of nitric oxide by endothelial cells. J Am Soc Nephrol 1997, 8:1431-1436.

22. Shiohira S, Kikuchi K, Yoshida T, Tsukada M, Nitta K, Akiba T: A case report of the effect of acetate-free biofiltration on arrhythmia in a hemodialysis patient. Ther Apher Dial 2007, 11:155-158.

23. Coll E, Perez-Garcia R, Rodriguez-Benitez P, Ortega M, Martinez MP, Jofre R, Lopez-Gomez JM: Clinical and analytical changes in hemodialysis without acetate. Nefrologia 2007, 27:742-748.

24. Bottger I, Deuticke U, Evertz-Prusse E, Ross BD, Wieland O: On the behavior of the free acetate in the miniature pig. Acetate metabolism in the miniature pig. Z Gesamte Exp Med 1968, 145:346-352.
25. Fournier G, Potier J, Thebaud HE, Majdalani G, Ton-That H, Man NK: Substitution of acetic acid for hydrochloric acid in the bicarbonate buffered dialysate. Artif Organs 1998, 22:608-613.

26. Bruegger D, Kemming GI, Jacob M, Meisner FG, Wojtczyk CJ, Packert KB, Keipert PE, Faithfull NS, Habler OP, Becker BF, Rehm M: Causes of metabolic acidosis in canine hemorrhagic shock: role of unmeasured ions. Crit Care 2007, 11:R130.

27. Chappell D, Jacob M, Hofmann-Kiefer K, Conzen P, Rehm M: A rational approach to perioperative fluid management. Anesthesiology 2008 109:723-740.

28. Prough DS, Bidani A: Hyperchloremic metabolic acidosis is a predictable consequence of intraoperative infusion of $0.9 \%$ saline. Anesthesiology 1999, 90:1247-1249.

doi:10.1186/2047-783X-17-21

Cite this article as: Hofmann-Kiefer et al:: Influence of an acetate- and a lactate-based balanced infusion solution on acid base physiology and hemodynamics: an observational pilot study. European Journal of Medical Research 2012 17:21.

\section{Submit your next manuscript to BioMed Central and take full advantage of:}

- Convenient online submission

- Thorough peer review

- No space constraints or color figure charges

- Immediate publication on acceptance

- Inclusion in PubMed, CAS, Scopus and Google Scholar

- Research which is freely available for redistribution

Submit your manuscript at www.biomedcentral.com/submit
C Biomed Central 